\title{
Pheromone mating disruption offers selective management options for key pests
}

\author{
Stephen C. Welter \\ Carolyn Pickel \\ Jocelyn Millar \\ Frances Cave \\ Robert A. Van Steenwyk \\ John Dunley \\ $\nabla$
}

The direct management of insect pests using pheromones for mating disruption, or "attract and kill" approaches, can provide excellent suppression of key lepidopteran pests in agriculture. Important successes to date include codling moth in pome fruit, oriental fruit moth in peaches and nectarines, tomato pinworm in vegetables, pink bollworm in cotton and omnivorous leafroller in vineyards. Large-scale implementation projects have yielded significant reductions in pesticide use while maintaining acceptably low crop-damage levels. Because of some difficulties with high populations of pests, these programs should not be viewed as stand-alone strategies but rather as one tactic within a suite of integrated pest management options.

P heromones, defined as chemicals secreted externally by an organism to send information to members of the same species, are used extensively by insects to communicate with each other. Pheromones may signal information as diverse as the sexual receptivity of the producer, perceived dangers or the dominance of an individual in a colony. Researchers have interfered with these communication systems as a means to selectively control or manage pest species in agricultural and forest systems.

A variety of approaches employ pheromones to manipulate or disrupt the natural behaviors of insects, such that population levels are reduced and crop damage diminishes. These strategies include mass trapping efforts over

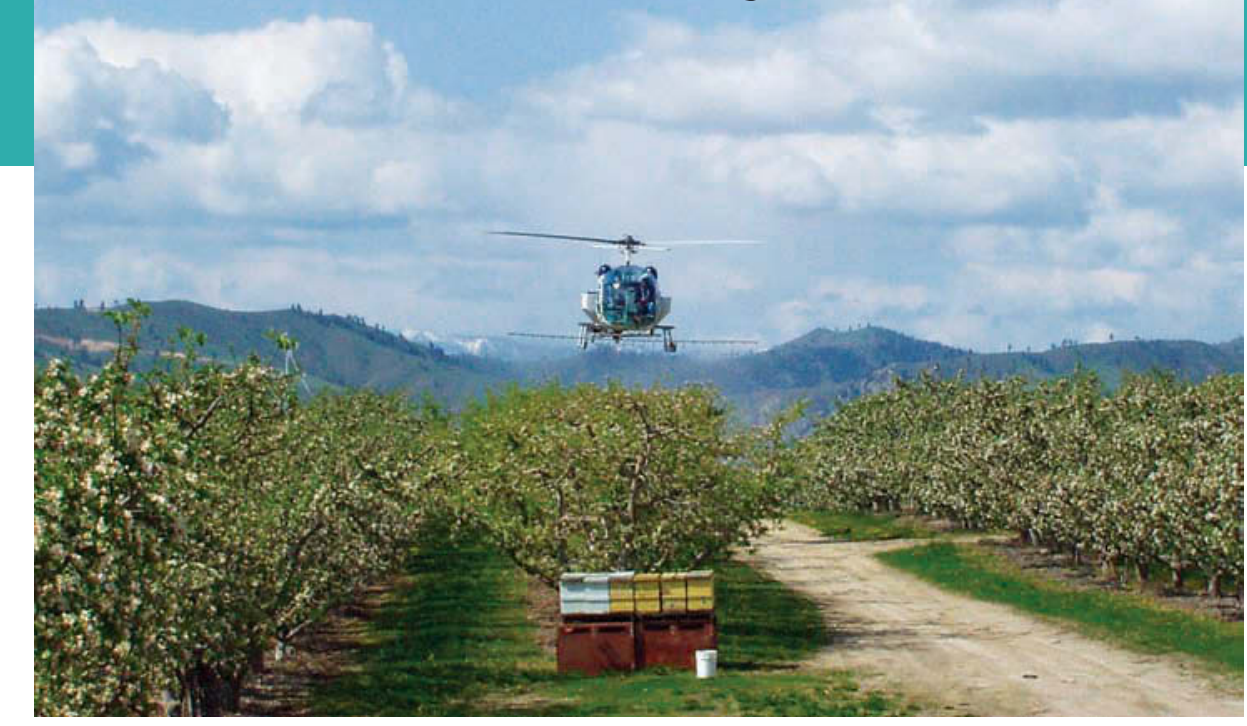

Pheromones are used by insects (and numerous other species) to communicate. When these messages are disrupted, pest insects fail to reproduce and mate. A sprayable formulation of microencapsulated pheromone is applied by helicopter.

huge expanses of forests or plantations, to the regional disruption of mating processes by pests, to smaller "attract and kill" approaches in specific fields. While many different groups of insects use pheromones, most successes to date have been with lepidopteran pests (butterflies and moths); these successes have allowed for more biologically intensive approaches to control pests.

\section{Advantages and disadvantages}

Many advantages of pheromonebased pest management systems are common to other biologically based management approaches, including virtually no detectable residues for some dispensing systems, negligible health risks, a more rapid registration process and no accumulation in wildlife or groundwater. Additional benefits include reduced worker re-entry or preharvest intervals and limited impacts on other management practices, such as irrigation scheduling. Pheromone-based mating disruption has also been identified as a strong tool for managing insecticide resistance. Whereas resistance to pheromones applied over broad areas might be expected, there is only one documented case of resistance, when an incomplete pheromone blend was deployed against the tea tortrix in Japan.
However, the correction of the blend eliminated the problem (Mochizuki et al. 2002).

A key benefit of pheromone-based programs is that they are highly selective. Typically, only the primary target species responds to the pheromone, and nontarget effects on biological control agents within a field or outside of a cropping system are not observed. The use of pheromones against key pests does not result in outbreaks of secondary pests or pest resurgence, creating opportunities for the biological control of other pest species.

However, the high degree of selectivity may also be a significant obstacle to large-scale implementation, in cases where secondary pests become a problem as insecticides are eliminated. Insecticide applications targeting the key pest sometimes inadvertently control other pests as a collateral benefit. For example, outbreaks of leafrollers (such as Pandemis pyrusana) have been reported in California apple orchards utilizing pheromone-disruption programs to control codling moth without organophosphates (OPs)(Walker and Welter 2001). Similar results were seen in apple orchards under a variety of programs using the mating disruption of codling moth (Nicholas et al. 1999); 
when the OP azinphos-methyl was removed, populations of the wooly aphid (Eriosoma lanigerum), lightbrown apple moth (Epiphyaas postvittana), San Jose scale (Quadraspidiotus perniciosus) and budworm (Helicoverpa spp.) increased.

Other possible limitations include: (1) the lack of an identified pheromone for some pest species; (2) high development and production costs; (3) requirements for specialized application techniques or equipment; and (4) the need to supplement the pheromone program in high pest-pressure situations. Pheromone programs are most effective with low to moderate population densities, whereas high-pressure situations in which damage from previous years exceeded $1 \%$ to $2 \%$ often require supplemental insecticide applications to prevent commercial damage. Treatment thresholds have been developed using modified pheromone lures, but they vary between crops and regions. Mating disruption, like most other pest management strategies, needs to be viewed within the context of an entire pest management system rather than as a stand-alone program.

Monitoring the target pest with pheromone traps also can become problematic, because the pheromones used to disrupt mating will also pre- vent moths from locating traps. Even in conventional fields, pheromone traps are rarely used as the sole indicator of pest problems; rather, they are often used in combination with other approaches, such as direct damage assessments. The use of high-dose lures that still attract some moths even under mating disruption has proven useful for tracking the flights of some pests (such as codling moth) or as a supplemental risk-assessment tool. Other species, such as oriental fruit moth (Cydia molesta), do not exhibit this response. However, it may be possible to develop nonpheromonal attractants for use in mating disruption (Light et al. 2001).

\section{Approaches in the field}

Mass trapping is a direct control strategy in which large numbers of pests are captured and removed. This strategy has been successful in controlling large weevils in tropical crops such as oil palms, palmito palms (grown for hearts of palm), plantains and bananas. In oil palm plantations in Central and South America, the palm weevil (Rhyncophorus palmarum) is a vector of the lethal red ring nematode. Pheromonebased mass trapping using one trap per acre is now the principal control method (Oehlschlager et al. 2002). The key bio-

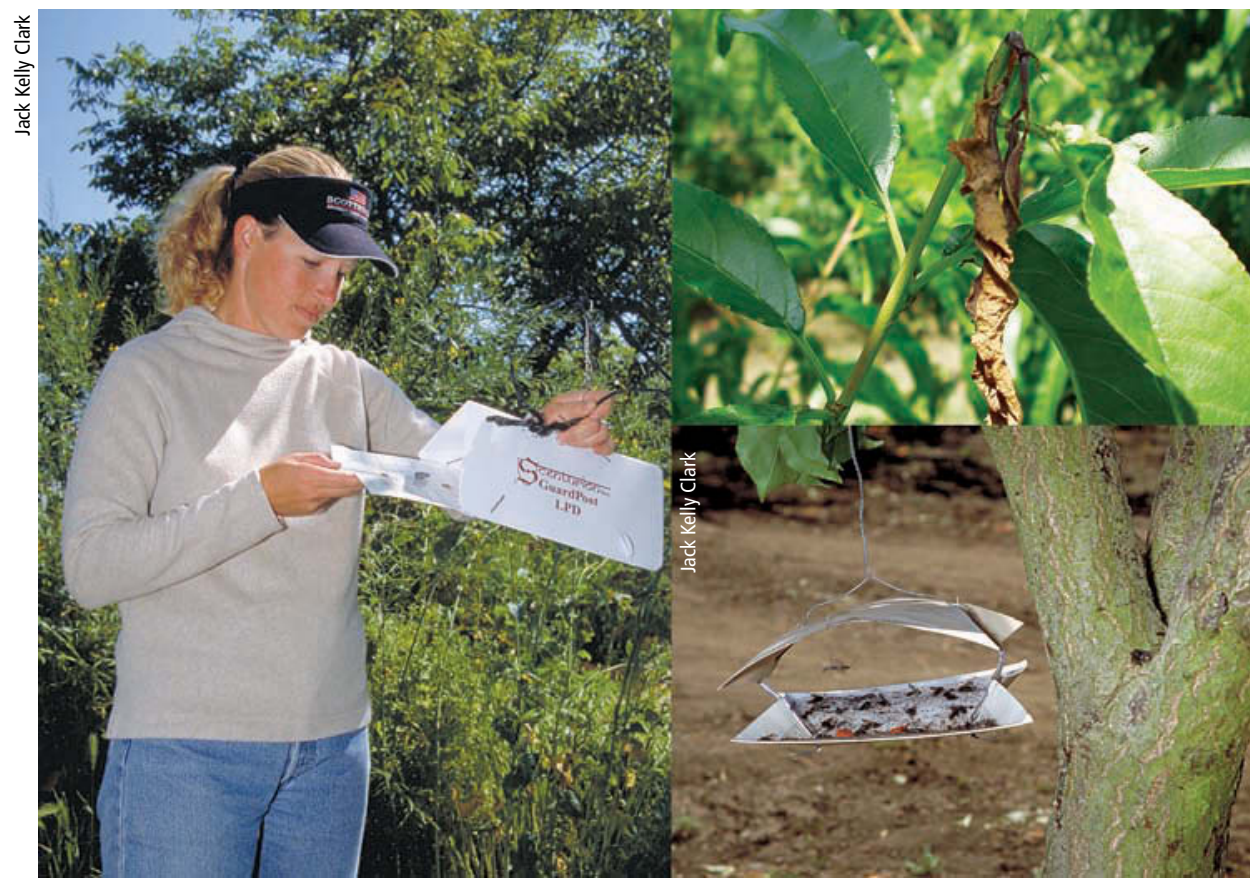

By carefully monitoring crop damage and insect populations, and applying pheromones to disrupt mating, growers have successfully protected orchard crops from insect pests. Left, former UC staff researcher Jeannine Lowrimore counts codling moths in a trap; top right, shoot-strike damage; bottom right, male peachtree borers in a pheromone trap.
Pheromones may signal

information as diverse as

the sexual receptivity of

the producer, perceived

dangers or the dominance

of an individual in a colony.

Researchers have interfered

with these communication

systems as a means to

selectively control or

manage pest species.

logical factors behind these successes appear to be the relatively long life and slow reproductive rate of the weevils, and the fact that the aggregation pheromones attract both sexes. Success is critically dependent on efficient masstrapping to remove weevils faster than they can reproduce.

In situations with other insects that do not have these biological characteristics, and particularly with sex pheromones that only attract one sex, mass trapping is generally less effective despite some larger projects collecting billions of individuals (Ryan 2002). It has been successful with smaller or confined populations such as those found on islands (the sugarcane wireworm [Melanotus okinawensis]) or with small, localized infestations of introduced pests targeted for eradication efforts, such as the white-spotted tussock moth (Orgyia thyellina) in New Zealand.

Pheromone-based mating disruption, which is the most commonly used approach, may work via a number of overlapping mechanisms that interfere with mate location and reproduction. Obviously, if males are prevented from locating or copulating with sufficient numbers of females, pest populations will decline. This approach works without the direct mortality of target individuals, preventing offspring and subsequent damage.

Attracticides, or "lure and kill" strategies, combine an attractant with an insecticide, eliminating individuals that contact the lure. Many limitations of mass trapping also apply to programs that target males only. Depending on how the system is implemented, it may also interfere with the male's location of 
Pheromones can be applied using a variety of dispensers, including (clockwise from top left): microencapsulated pheromones, sprayed like insecticides; hand-applied dispensers, with a reservoir and permeable membrane to regulate release; hollow fibers; and twist-tie ropes.

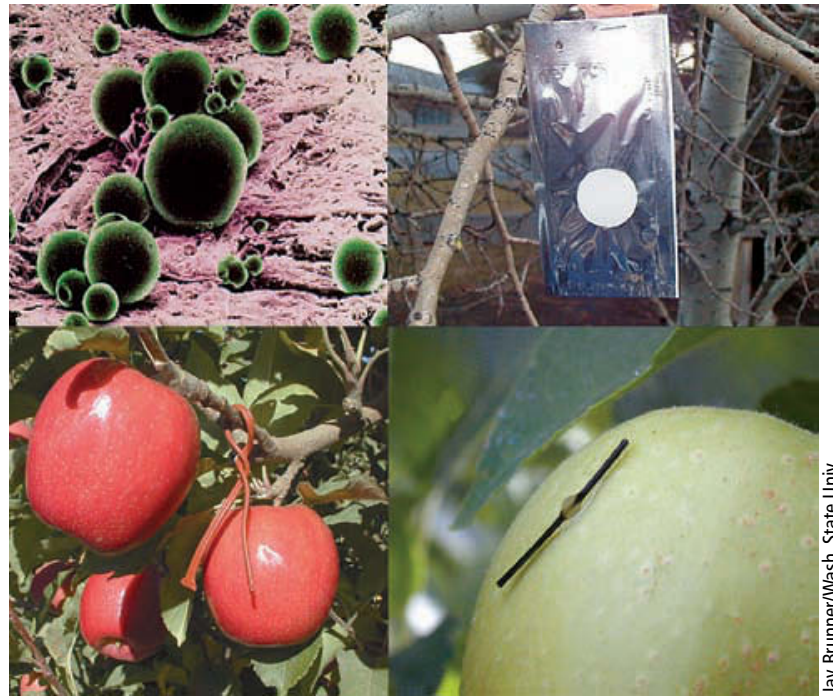

females through false trail-following, as well as the primary effect of the male's attraction to insecticide-laced baits.

\section{Mechanisms of mating disruption}

Limitations to developing mating disruption programs include a lack of understanding about the mechanisms of mating disruption for different types of dispensers, the biological or behavioral characteristics of the target pest, and how pheromones move and distribute themselves within agricultural systems (Cardé and Minks 1995; Sanders 1997). Surprisingly, the principle mechanisms of action for even some of the most successful programs (such as codling moth in pome fruit) are unclear.

Researchers have shown that the pheromone plume is not a uniform cloud, but rather a series of filaments of pheromone interspersed with pockets of zero to low concentrations due to natural turbulence in the air (Sanders 1997). The male is exposed to a series of rapidly changing concentrations, which requires both the interpretation of the odor and a resetting of the antennal receptors within milliseconds to perceive the next pheromone molecule (Leal 2003). The male proceeds to fly upwind in a series of surges interspersed with crosswind casting when it detects pockets of air with reduced concentrations of pheromone. For most species, a turbulent plume with pockets of high and low concentrations is required for proper upwind flight; if a column of air is filled uniformly with pheromone, then the sensory structures may fatigue and no longer respond to the pheromone.

Sanders (1997) and Cardé and Minks (1995) have reviewed different mecha- nisms of mating disruption. Sensory adaptation is a reduction in the firing rates of the sensory structures after prolonged exposure to the pheromone, whereas habituation is a reduction in the insect's response to the pheromone due to some change in the central nervous system. Both of these mechanisms can generate the same nonresponsive outcome. Different species respond differently to prolonged exposures in pheromone-treated fields. Habituation, which may result in arrested movement, has been proposed as a possible mechanism for high-dose exposures from devices that periodically release pheromones in large aerosol puffs (puffers), or in close proximity to passive dispensers. Both can occur with either complete or partial pheromone blends.

The camouflage of a female's pheromone plume presumes that the overlapping plumes from multiple pheromone dispensers generate a "fog" of pheromone, so that the males can no longer distinguish the pheromone emitted by a female from the elevated background. The false-trail-following mechanism produces direct competition between calling females and synthetic dispensers, as males spend time and energy locating "false females." This diversion of the male's activities results in either a decrease in the proportion of females mated or a delay in mating.

The proposed mechanisms by which mating disruption might work are not mutually exclusive, and several mechanisms may be important for the same insect under different conditions. For example, Cardé et al. (1998) demonstrated that the mating disruption of the pink bollworm occurs from a combina- tion of mechanisms including camouflage, competition between pheromone dispensers and females, habituation, and some advancement of the rhythm of the male's response to the female's pheromone, which may result in asynchrony in sexual behaviors.

The use of antagonistic compounds, agonists, pheromone mimics and synergists is broadly grouped under the term parapheromones, loosely defined as anthropogenic compounds structurally related to natural pheromone compounds that affect the behavior or physiology of the insect's communication system (Renou and Guerrero 2000). This group includes compounds of plant origin used to annihilate (with an attractant plus a lethal agent) the males of important dipteran pests, such as bait sprays for fruit flies or walnut husk flies. While parapheromones alter neural activity, change insect behaviors and depress or synergize trap capture, their utility in the field for management purposes has received limited testing and remains highly variable.

However, studies have also shown that even in programs with minimal crop damage, significant mating may still occur. Alternative mechanisms are being explored that focus on the effects of delaying mating rather than its complete suppression. Delays in mating by virgin females or males has been shown in multiple species to result in depressed egg-laying and increased sterility of the eggs laid (Jones and Aihara-Sasaki 2001; Fadamiro and Baker 1999). Therefore, exclusive focus on the complete prevention of mating may not be warranted. Mating disruption still remains a useful term if disruption is to include both the prevention of mate location and mating, and factors that interfere with or delay the normal mating processes.

\section{Pheromone-dispensing technologies}

A variety of dispensing technologies have shown promise and success under commercial conditions and are now available to growers. Each varies in terms of ease of application, cost and the mechanism of disruption. Challenges for pheromone dispensers include protecting components from degradation by environmental factors and the uniform release over time of different types of compounds (such as aldehydes, alco- 
hols or acetates) with varying chemical and physical properties.

MECs. Microencapsulated pheromones (MECs) are small droplets of pheromone enclosed within a polymer capsule, which controls the pheromone release rate. The capsules are small enough to be applied as suspensions with the same commercial equipment used to spray insecticides. The effective field longevity of these materials generally ranges from days to weeks depending on climatic conditions, capsule size and properties, and the chemistry of the pheromone components. However, the material is applied directly to the commodity, an important consideration in food crops.

Hand-applied dispensers. Larger, hand-applied dispensers include systems with an impermeable reservoir fitted with a permeable membrane for regulating pheromone release, and analogous laminate dispensers that consist of a central pheromone-containing core sandwiched between two polymer films. These dispensers can be cut into various shapes and sizes ranging from larger, hand-applied dispensers to smaller, confetti-like flakes that can be applied by specialized ground or air applicators. Pheromones can be mixed into paraffin wax or aqueous paraffin emulsions and applied directly to the tree using hand-dispensers (Atterholt et al. 1999) or potentially in modified sprayers.

Hand-applied dispensers also include pheromone-impregnated polymer spirals, and twist-tie "ropes" that consist of a pheromone-filled plastic tube with a wire spline along one side. The wire allows these dispensers to be twist-tied directly to the plant or hung indirectly with a clip. New technologies using alternative "rope dispensers" without a spline have been developed as well. The larger reservoirs of the hand-applied dispensers (ropes, laminate systems, spirals) allow for effective lifetimes of 60 to 140 days, such that single applications early in the season may suppress mating all season.

Hollow fibers. Hollow fibers have been employed since the 1970s in mating disruption programs. The fibers consist of a short, impermeable plastic tube that is sealed at one end and filled with pheromone. After an initial burst

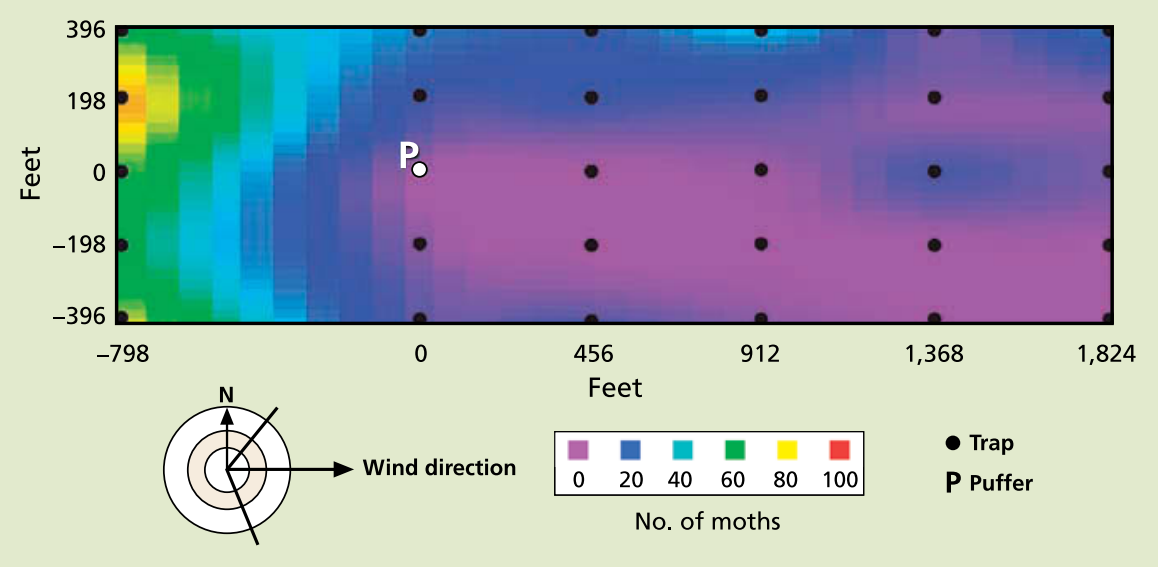

Fig. 1. Downwind area of trap suppression by a single puffer with a 12-hour "on" cycle, placed in a walnut orchard coincidental with the release of a uniform grid of sterile, marked codling moth. Number of moths is 5-day cumulative trap-catch total.

of pheromone from the fiber, this technology has a relatively constant emission rate over time. These fibers are often combined with an adhesive material during application and may require specialized ground or air equipment to apply.

High-emission dispensers. Highemission dispensers were developed to emit larger quantities of pheromone and use fewer dispensers per acre to cut down on labor costs (Shorey and Gerber 1996; MafraNeto and Baker 1996). The only commercially available dispenser of this type at this time is the Suttera puffer. The puffer uses a pressurized aerosol can filled with a pheromone, which dispenses metered puffs of pheromone at fixed time intervals (such as every 15 minutes). The number of units per acre varies depending on orchard size and patterns of distribution, but approximately one-half to one dispenser per acre is typical for codling moth in pears.

Recent research attempting to define the effective area of trap suppression of codling moth, using uniform releases of sterile moths, revealed a surprisingly long plume that was typically greater than 1,500 feet long and between 300 and 500 feet wide (fig. 1). In addition, researchers are beginning to test the possibility of using large, passive-release devices consisting of polymer bags loaded with large doses of pheromones (Mahr and Baker 2001). These devices are intended to work in the same general way as puffers, but with no batteries or moving parts they are potentially more reliable.

\section{Current uses to control insects}

Pheromone-based devices have achieved the successful control of insect pests in almost all types of agriculture, including perennial orchards, vineyards, annual vegetables and fiber crops. The following five insect pests have enjoyed historical and recent successes with pheromone-based management systems.

Codling moth. A recent success involves the management of codling moth in pear and apple orchards in California and the Pacific Northwest (Calkins and Faust 2003)(fig. 2). In 2001, the mating disruption of codling moth was used on about 135,000 acres of pome fruit, or roughly $45 \%$ to $50 \%$ of the acreage from the Sacramento Valley to the Pacific Northwest. Adoption rates in southern

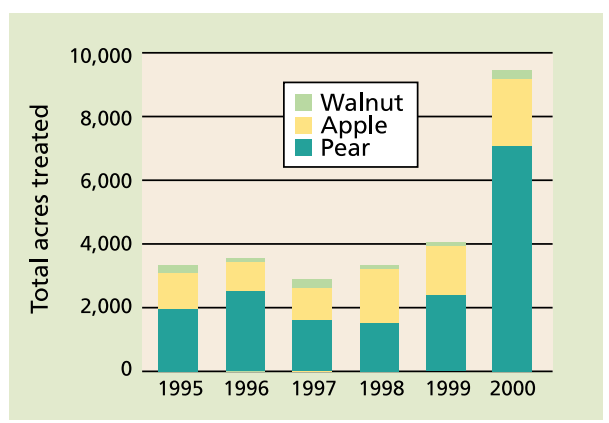

Fig. 2. Codling moth pheromone applications in California in walnuts, apples and pears. To show use trends rather than absolute rates, data includes all delivery technologies and multiple applications to the same acre within a year. Sources: UC Integrated Pest Management Web site, www.ipm.ucdavis.edu; California Department of Pesticide Regulation pesticide-use tracking data. 


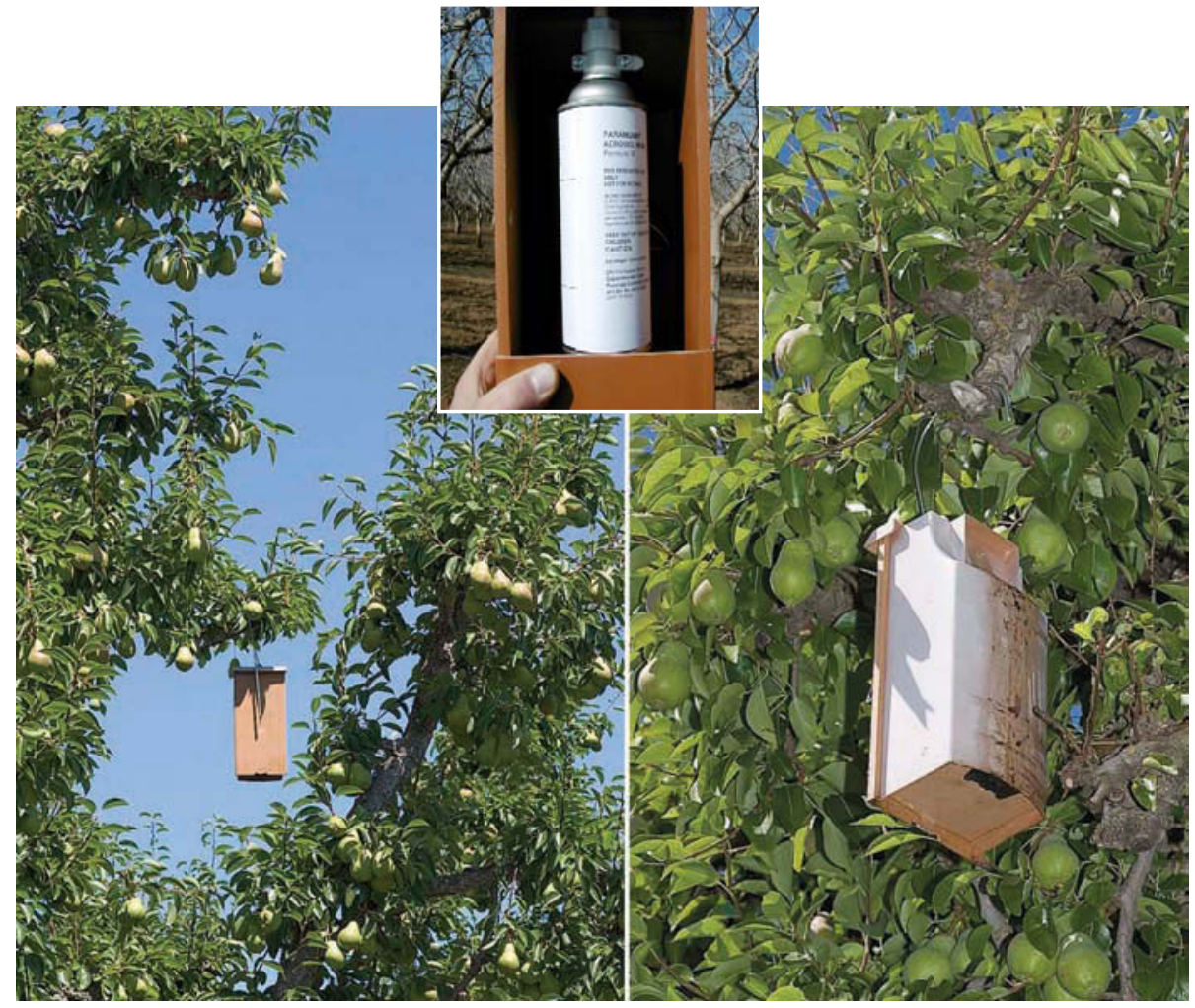

apple-growing regions are lower due to higher pest population levels, presumably the result of more generations per year. While the dominant release device from 1995 to 2000 was hand-applied dispensers (Isomate $\mathrm{C}+$ rope dispensers and Checkmate CM laminate dispensers), others such as puffers were successfully used on more than 1,300 acres of pears in Lake County.

The use of mating disruption in pome fruit accelerated after the development of the first such areawide program in the Randall Island region of the Sacramento River Delta in 1993. Five growers and their pest control advisors committed 760 contiguous acres to a long-term program to reduce codling moth populations over time, using a combination of mating disruption and reduced insecticide. Codling moth populations in an organic apple orchard directly across the river plus additional conventional sites were used for comparison.

In the Randall Island project, population levels in pheromone-treated areas - as documented by mean trap counts - were reduced over the 6-year period to less than 10 moths per trap from highs of about 80 moths per trap (fig. 3). Fruit damage was held to less than $1 \%$ in all years with final damage levels for 1998 to 1999 of less than $0.1 \%$. The number of insecticide applications for codling moth was reduced $75 \%$, from an average of four to approximately one per season.

This pattern was repeated with four additional areawide sites, initiated by a team of entomologists from UC, Oregon State University, Washington State University and the U.S. Department of Agriculture's Agricultural Research Service in Wapato, Wash. Ultimately, 17 additional sites were established in four Western states. Although the areawide research programs are no longer active, the infrastructure and momentum developed have allowed the approach to flourish. Studies have shown that codling moth also can be controlled in walnuts with hand-applied dispensers in smaller, more limited trials, but program costs were higher than conof application to larger-canopied trees (Grant et al. 2003). A similar result was achieved in an areawide program in Lake County by Cooperative Extension, local pest control advisors and growers using pheromone "puffers" on more than 1,300 acres owned by 15 growers.

Tomato pinworm. The mating disruption of tomato pinworm (Keiferia lycopersicella) was originally developed using hollow fibers in the 1970s and 1980s (Van Steenwyk and Oatman 1983). It has been particularly successful in Mexico, where conventional ventional programs given the high costs
In Lake County, 15 pear growers utilized high-dose "puffer" dispensers on about 1,300 acres. The high-dose aerosol cans, inset, are hung high in trees, releasing the pheromones at regular intervals.

insecticide programs were failing because of extraordinary levels of resistance that jeopardized the whole industry by the late 1980s (Trumble 1997). Some damage suppression was achieved in cherry tomatoes, but damage levels were still variable and excessive in both conventional insecticide and pheromone-treated plots. A pest management program was developed to address resistance issues and provide a more sustainable system, while considering its overall economics. For winter and spring plantings, conventional sites suffered excessive damage of $75 \%$ to $90 \%$, while damage was reduced to $33 \%$ to $35 \%$ in the IPM plots.

Overall economic evaluations demonstrated substantial economic returns from the IPM program compared to conventionally treated plots. Pheromone treatment remains relatively local and site-specific in California given that tomato pinworm is a greater pest in fresh-market than processing tomatoes. Newer products, including hand-applied or sprayable formulations, have been introduced. However, the use of the tomato pinworm mating-disruption program was fairly flat from 1995 until 2000, when an increase occurred (fig. 4).

Pink bollworm. Pink bollworm (Pectinophora gossypiella) has been the target of an intensive, long-term and successful mating-disruption effort (Staten et al. 1997) in both the United States and abroad. A variety of strategies have been employed, including applications of hollow fibers, chopped laminate flakes, sprayable microencapsulated pheromone, twist-tie ropes or laminate membrane dispensers. Problems with successful mating disruption in fields with high moth populations were detected and supplemental control tactics were used. Combinations of sterile insects and mating disruption were implemented in large-scale programs in 
the Imperial and Mexicali valleys.

Successful mating disruption in the late 1980s in the Coachella Valley resulted in significant decreases in insecticide use (7.3 applications in 1985 to no treatments in 1988). However, the immigration of mated moths from the Imperial Valley to the Coachella Valley in 1989 appears to have resulted in decreased program efficacy. The isolation and areawide suppression of populations improved the efficacy of the mating disruption program, similar to later experiences with codling moth. A recent, interesting twist is the introduction of transgenic cotton with the Bt gene, which has been reported as highly effective against pink bollworm. Mating disruption has declined with

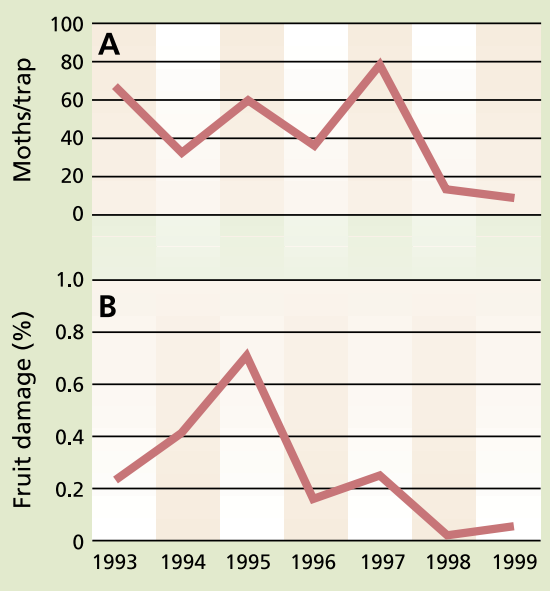

Fig. 3. Codling moth (A) trap totals and (B) damage levels for the season in pheromonetreated plots in the Randall Island project.

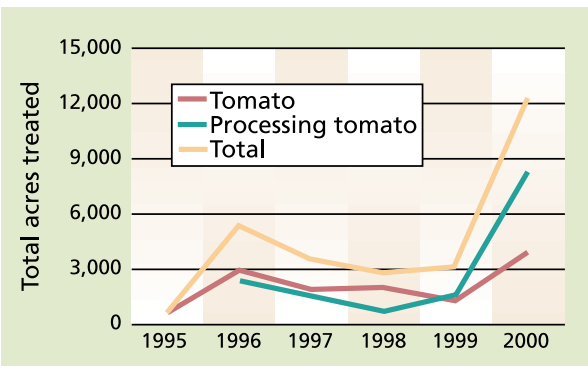

Fig. 4. Tomato pinworm pheromone use in California for processing and fresh-market tomatoes. Data from DPR includes all delivery technologies and multiple applications to the same acre within a year. Sources: see figure 2. the introduction of Bt cotton, except in areas under the pink bollworm eradication program that are not using transgenic cotton.

Oriental fruit moth. Mating disruption has been used worldwide to control oriental fruit moth in stone fruit, peaches and nectarines using both hand-applied and sprayable formulations (Pickel et al. 2002). In 1995, a series of replicated field plots was established in California to evaluate three handapplied dispensers (laminate, membrane and rope dispenser) in peach orchards. Season-long control was achieved, with approximately $34 \%$ of the orchards having no detectable damage and $63 \%$ having less than 3\% damage, the current processor standard. However, typically one orchard out of 21 in each year had damage in excess of $3 \%$, which again reinforced that mating disruption in orchards with high moth populations needs to be supplemented with other control strategies. Overall full-season costs for the pheromone program were significantly higher than for conventional treatments, such that growers developed a modified program using a single application of the hand-applied pheromone dispensers supplemented with insecticides later in the season. The partial pheromone program appears to be more cost effective at this time.

More recently, both puffer-type dispensers and sprayable microencapsulated formulations have seen some use. Oriental fruit moth is an easily disrupted pest, resulting in a large increase in applications from 1995 to 2000 (fig. 5). Increased adoption rates will depend on growers' perception of risk from oriental fruit moth, the availability of effective, less expensive insecticide alternatives, and the complex of pests within the orchard.

Omnivorous leafroller. The mating disruption of omnivorous leafroller with hand-applied or sprayable formulations has increased since 1998 in California vineyards, with more than 35,000 acre-applications made. Given that this pest is only important in the state's warmer grape-growing regions, the need for pheromones is geographically

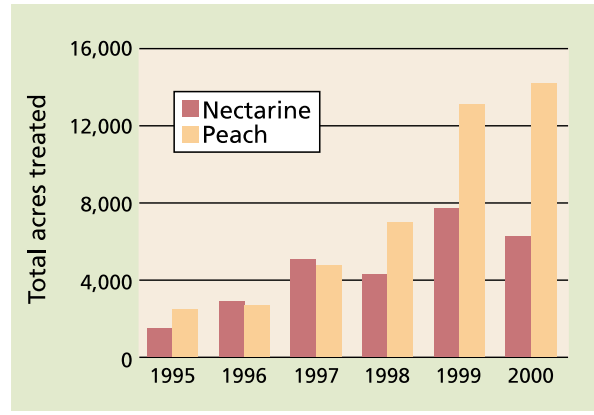

Fig. 5. Oriental fruit moth pheromone applications in California peaches and nectarines. Data from DPR includes all delivery technologies and multiple applications to the same acre within a year. Sources: see figure 2 .

restricted. Sprayable formulations may be preferable to address more-local or less-severe infestations of omnivorous leafrollers, a pest that is unpredictable in distribution and severity.

\section{Future directions}

While mating disruption provides an excellent management option for reducing insecticide use, it often requires supplemental insecticides to control high pest populations. The successful implementation of mating disruption will require curative, rapid treatments to address increasing or unexpected population surges. As outlined in Metcalfe et al. (2002), the implications of eliminating OP insecticides will depend on the existence of alternative strategies, yet the implementation of pheromones may also require development of selective insecticides as supplements.

Programs are being developed to address other lepidopteran pests in systems for which the key insects may be managed by pheromones or other selective management tools. As key pests like codling moth come under control, research is under way to improve the mating disruption of other orchard pests, such as the oblique-banded leafroller (Choristoneura rosaceana) and Pandemis leafroller (Pandemis pyrusana). Research is also ongoing in programs that have had partial success, such as for navel orangeworm (Amyelois transitella). Opportunities with storedproduct pests such as the Indian meal 
moth (Plodia interpunctella [Hubner]) or Angoumois grain moth (Sitotroga cerealella) are being explored (Fadamiro and Baker 2002). While most successes have been with lepidopteran insects, research in other insect orders - such as Heteroptera (e.g., stink bugs) or Coleoptera (beetles) - is promising (McBrien et al. 2002; Millar et al. 2002).

Some pests are highly mobile and better suppressed at regional rather than local scales. Coordinated areawide efforts have been much more effective than patchworks of treated and untreated areas. Newer formulations such as puffers, attract-and-kill formulations and sprayable formulations are offering opportunities to increase program flexibility, mix strategies and reduce costs.

Perhaps the greatest challenges lie with understanding the mechanisms of mating disruption systems for different target species and dispensers, which will allow the design of better applications and protocols. Finally, the implementation of mating disruption may require a shift in the scale at which growers, pest management consultants, extension specialists and university researchers approach management systems, given that overall program performance is strongly correlated with large-scale, multigrower implementation efforts.

\footnotetext{
S.C. Welter is Professor and Chair of Insect Biology, Department of Environmental Science, Policy, and Management, UC Berkeley; C. Pickel is IPM Advisor, UC Cooperative Extension, Sutter/Yuba Counties; J. Millar is Professor, Department of Entomology, UC Riverside; F. Cave is Research Associate, and R.A.Van Steenwyk is Cooperative Extension Entomologist, Department of Environmental Science, Policy, and Management, UC Berkeley; and J. Dunley is Associate Professor, Department of Entomology, Washington State University, Wenatchee, Wash.
}

\section{References}

Atterholt CA, Delwiche MJ, Rice RE, Krochta JM. 1999. Controlled release of insect sex pheromones from paraffin wax and emulsions. J Controlled Release 57:233-47.

Calkins CO, Faust RJ. 2003. Overview of areawide programs and the program for suppression of codling moth in the western USA directed by the United States Department of Agriculture - Agric. Res. Service. Pest Manage Sci 9:601-4.

Cardé RT, Minks AK. 1995. Control of moth pests by mating disruption - successes and constraints. Annu Rev Entomol 40:559-85.

Cardé RT, Staten RT, Mafra-Neto A. 1998. Behaviour of pink bollworm males near highdose, point sources of pheromone in field wind tunnels: Insights into mechanisms of mating disruption. Entomol Experimentalis Applicata 89:35-46.

Fadamiro HY, Baker TC. 1999. Reproductive performance and longevity of female European corn borer, Ostrinia nubilalis: Effects of multiple mating, delay in mating, and adult feeding. J Insect Phys 45:385-92.

Fadamiro HY, Baker TC. 2002. Pheromone puffs suppress mating by Plodia interpunctella and Sitotroga cerealella in an infested corn store. Entomologia Experimentalis Applicata 102:239-51.

Grant JA, Bentley W, Pickel C, GrohLowrimore J. 2003. BIOS approach tested for controlling walnut pests in San Joaquin Valley. Cal Ag 57:86-92.

Jones VP, Aihara-Sasaki M. 2001. Demographic analysis of delayed mating in mating disruption: A case study with Cryptophelbia illepida (Lepidoptera: Tortricidae). J Econ Entomol 94:785-92.

Leal WS. 2003. Proteins that make sense. In: Blomquist GJ, Vogt RG (eds.). Insect Pheromone Biochemistry and Molecular Biology. Amsterdam: Elsevier Ac Pr. p 447-76.

Light DM, Knight AL, Henrick CA, et al. 2001. A pear-derived kairomone with pheromonal potency that attracts male and female codling moth, Cydia pomonella (L.). Naturwissenschaften 88:333-8.

MafraNeto A, Baker TC. 1996. Timed, metered sprays of pheromone disrupt mating of Cadra cautella (Lepidoptera: Pyralidae). J Agric Entomol 13:149-68.

Mahr D, Baker TC. 2001. Mating disruption for insect control: Where are we? In: Proc 2001 Wisconsin Cranberry School. Univ WI, Madison. p 1-4.

McBrien HL, Millar JG, Rice RE, et al. 2002. Sex attractant pheromone of the redshouldered stink bug Thyanta pallidovirens: A pheromone blend with multiple redundant components. J Chem Ecol 28:1797-818.

Metcalfe M, McWilliams B, Hueth B, et al. 2002. The Economic Impact of Organophosphates in California Agriculture. California Department of Food and Agriculture Report.
Sacramento, CA. 41 p. + app. http://www. cdfa.ca.gov/publications.htm

Millar JG, Daane KM, McElfresh JS, et al. 2002. Development and optimization of methods for using sex pheromone for monitoring the mealybug Planococcus ficus (Homoptera: Pseudococcidae) in California vineyards. J Econ Entomol 95:706-14.

Mochizuki F, Fukumoto T, Noguchi $\mathrm{H}$, et al. 2002. Resistance to a mating disruptant composed of (Z)-11-tetradecenyl acetate in the smaller tea tortrix, Adoxophyes honmai (Yasuda)(Lepidoptera: Tortricidae). Appl Entomol Zool 37:299-304.

Nicholas AH, Thwaite WG, SpoonerHart RN. 1999. Arthropod abundance in an Australian apple orchard under mating disruption and supplementary insecticide treatments for codling moth, Cydia pomonella (L.)(Lepidoptera: Tortricidae). Austral J Entomol 38:23-9.

Oehlschlager AC, Chinchilla C, Castillo G, Gonzalez L. 2002. Control of red ring disease by mass trapping of Rhynchophorus palmarum (Coleoptera: Curculionidae). Flor Entomol 85:507-13.

Pickel C, Hasey J, Bentley W, et al. 2002. Pheromones control oriental fruit moth and peach twig borer in cling peaches. Cal Ag 56:170-6.

Renou M, Guerrero A. 2000. Insect parapheromones in olfaction research and semiochemical-based pest control strategies. Annu Rev Entomol 45:605-30.

Ryan MF. 2002. Pheromones in Plant Protection. Dordrecht: Kluwer Acad Publ. p 256-78.

Sanders CJ. 1997. Mechanisms of mating disruption in moths. In: Cardé RT, Minks AK (ed.). Insect Pheromone Research: New Directions. New York: Inter Thomson Pub. p 333-58.

Shorey HH, Gerber RG. 1996. Disruption of pheromone communication through the use of puffers for control of beet armyworm (Lepidoptera: Noctuidae) in tomatoes. Environ Entomol 25:1401-5.

Staten RS, El-Lissy O, Antilla L. 1997. Successful area-wide program to control pink bollworm by mating disruption. In: Cardé RT, Minks AK (ed.). Insect Pheromone Research: New Directions. New York: Inter Thomson Pub. p 383-97.

Trumble JT. 1997. Integrating pheromones into vegetable crop production. In: Cardé RT, Minks AK (ed.). Insect Pheromone Research: New Directions. New York: Inter Thomson Pub. p 379-410.

Van Steenwyk RA, Oatman ER. 1983. Mating disruption of tomato pinworm (Lepidoptera, Gelechiidae) as measured by pheromone trap, foliage, and fruit infestation. J Econ Entomol 76:80-4.

Walker KR, Welter SC. 2001. Potential for outbreaks of leafrollers (Lepidoptera: Tortric idae) in California apple orchards using mating disruption for codling moth suppression. J Econ Entomol 94:373-80. 